\title{
Gene expression analysis in combat veterans with and without post-traumatic stress disorder
}

\author{
MICHAEL HOLLIFIELD ${ }^{1,2}$, DAN MOORE ${ }^{3,4}$ and GARRET YOUNT ${ }^{4}$ \\ ${ }^{1}$ Behavioral Health Research Center of the Southwest, Albuquerque, NM 87102; ${ }^{2}$ The VA Long Beach Healthcare System, \\ Long Beach, CA 90822; ${ }^{3}$ Department of Epidemiology and Biostatistics, University of California San Francisco, \\ San Francisco, CA 94107; ${ }^{4}$ California Pacific Medical Center Research Institute, San Francisco, CA 94107, USA
}

Received November 13, 2012; Accepted March 1, 2013

DOI: $10.3892 / \mathrm{mmr} .2013 .1475$

\begin{abstract}
Post-traumatic stress disorder (PTSD) is a common, debilitating and complex disorder. Numerous genetic and environmental factors are important in the genesis and maintenance of PTSD. Thus, gene expression analysis (GEA) is a critical technology for PTSD research since it detects essential genetic output affected by gene-environment interactions. Quality control methods are rarely reported in gene expression studies. The present study aimed to identify reliably expressed genes in whole blood samples from subjects with combat-induced PTSD ( $\mathrm{n}=6)$ and, secondly, to investigate the expression of genes that may be differentially expressed in PTSD compared with an appropriate control group $(n=11)$. Strict quality control methods were used. From a theoretically driven set of 42 genes, 17 were reliably detected using quantitative PCR on samples from 17 combat-exposed veterans. Four of these 17 genes were consistently and modestly correlated with clinical phenotypes and had significant expression effects on phenotypes. These genes regulate inflammatory systems and are regulated by the adrenergic system, consistent with peripheral markers important in PTSD. Inflammatory disinhibition may be involved in combat-induced PTSD, and may be responsible for the increased prevalence of inflammatory-related illnesses observed in PTSD. This is a preliminary study with a small sample size. A number of genes are not reliably detected by the current methodology. Improved detection methods are important to extend the current study and to further understand mechanisms in PTSD.
\end{abstract}

\section{Introduction}

Gene expression analysis (GEA) is well-suited for identifying genetic effects on complex disorders. Post-traumatic

Correspondence to: Dr Michael Hollifield, The VA Long Beach Healthcare System (06/116A), Suite 102A, Building 128, 5901 East 7th Street, Long Beach, CA 90822, USA

E-mail: michael.hollifield@va.gov

Key words: stress, mental health, gene expression stress disorder (PTSD) is a complex illness with highly variable phenotypic and endophenotypic traits that arise from gene-environment interactions (1). The heterogeneous clinical symptoms parallel broad biological dysfunction in the hypothalamic-pituitary axis (HPA) (2-10) and autonomic (ANS) $(4,11-13)$ and central nervous system (CNS) functions (14-17). Previous studies have provided evidence for a low level pro-inflammatory state in PTSD (18-22). The CNS areas involved are central regulators of the HPA axis and the ANS, and this coordinated dysfunction in PTSD is compatible with inflammatory disinhibition.

Differentially expressed genes identified in previous GEA studies of PTSD (23-26), consistent with case-control candidate gene association studies, have a role in regulating the HPA axis, the ANS and CNS, and more specifically in immune activation, inflammation, signal transduction and apoptosis, similar to biological systems implicated by non-gene biological studies of PTSD (27). The present study reports preliminary data that shows the importance of quality control methods in GEA studies and the possible differential expression of genes regulating pathways between the HPA, ANS and inflammation in PTSD.

\section{Materials and methods}

Study design and participants. Subjects for this case-control study were recruited from military personnel aged 18-65 years in Albuquerque (NM, USA) using flyers, word of mouth and snowball sampling. All the subjects had significant combat exposure in Iraq or Afghanistan. Exclusions included substance dependence (six months), psychosis, uncontrolled medical illness, current medications for PTSD, opioid use, benzodiazepine use equivalent to $>10 \mathrm{mg}$ diazepam, known exposure to neurotoxic chemicals, pregnancy and suicide risk. Study procedures were in accordance with the latest version of the Declaration of Helsinki and were approved by the IRB at the Pacific Institute for Research and Evaluation (PIRE; Calverton, MD, USA).

Phone screening was conducted by a research assistant (RA). Qualifying subjects were clinically assessed by the RA and a co-investigator after providing written informed consent. Thirty-two subjects were contacted. Eleven declined or were excluded during screening, and two were excluded at 
Table I. Demographic and clinical characteristics by post-traumatic stress disorder (PTSD) status [mean (SD)].

\begin{tabular}{lcccc}
\hline Characteristics & $\begin{array}{c}\text { PTSD } \\
(\mathrm{n}=6)\end{array}$ & $\begin{array}{c}\text { No PTSD } \\
(\mathrm{n}=11)\end{array}$ & $\mathrm{F}$ & P-value \\
\hline Age (years) & $31(4.9)$ & $33.4(10.1)$ & 0.29 & 0.60 \\
Education (years) & $13.7(2.1)$ & $15.0(1.1)$ & 3.1 & 0.10 \\
Household size (n) $^{2}$ & $2.8(1.8)$ & $2.4(1.2)$ & 0.41 & 0.52 \\
Income $^{\mathrm{a}}$ & $3.3(1.5)$ & $3.4(1.5)$ & 0.00 & 0.97 \\
Work (h/week) & $20.0(21.9)$ & $36.2(16.1)$ & 3.06 & 0.10 \\
CES & $23.0(4.4)$ & $18.5(6.4)$ & 2.37 & 0.14 \\
Anx & $2.2(0.6)$ & $1.3(.40)$ & 11.41 & $<0.01$ \\
Dep & $22.7(5.0)$ & $7.7(6.5)$ & 24.00 & $<0.01$ \\
PTSD & $75.3(11.6)$ & $17.4(15.2)$ & 65.67 & $<0.01$ \\
\hline
\end{tabular}

ancome (annual): 0, \$0-15,000; 1,\$15,001-20,000; 2, \$20,001-25,000; 3, $\$ 25,001-30,000 ; 4, \$ 30,001-40,000 ; \quad 5,>\$ 40,001$. CES, Combat Experiences Scale; Anx, Hopkins Symptoms Checklist anxiety scale item average; Dep, Beck Depression Inventory II; PTSD, Clinician-Administered PTSD Scale total score.

clinical assessment. Nineteen were enrolled and 17 completed the study. Table I shows demographic, trauma and clinical status by group (PTSD and no PTSD). Following the recruitment of 12 subjects (6 PTSD, 6 no PTSD), five with no PTSD symptoms were oversampled to include a broad range of phenotypes, since five of the initial six controls had mild or moderate, non-diagnostic level symptoms.

Clinical assessments. A history form, an abridged version of the Structured Clinical Interview for Diagnosis (28) and the Clinician-Administered PTSD Scale (CAPS) (29) were used to determine study qualification and PTSD symptoms and diagnosis.

The Combat Exposure Scale (30) assessed combat exposure severity. The Beck Depression Inventory-II (BDI-II) (31) and the Hopkins Symptom Checklist-25 anxiety scale (HSCLA) (32) assessed the symptoms and severity of depression and anxiety, respectively. Both continuous and dichotomous scoring was utilized for analyses.

Candidate gene selection. Genes of interest were selected due to extant data with regard to the potential regulatory link between the HPA, ANS and inflammatory systems in PTSD (Fig. 1). Inclusion on a 42-gene panel required that their products are regulated under conditions pertinent to PTSD and activation of systemic inflammation, or that they encode receptors or transporters for these key regulators. Additionally, inclusion required published evidence that the genes are expressed in peripheral blood cells.

Laboratory protocol. Subjects were provided with written instructions and a telephone review the day before the study with regard to the protocol as follows: no food, smoking or caffeine use after midnight, and arrival at the laboratory at 8:00 am to stay for up to $1 \mathrm{~h}$.
Table II. Demographic, trauma and major clinical phenotype scores by subject.

\section{Patient PTSD}

no. diagnosis Age Gender Edu CES Anx Dep PTSD

\begin{tabular}{rlrlrrrrr}
\hline 1 & No & 25 & M & 16 & 15 & NA & 6 & 17 \\
2 & No & 31 & F & 14 & 24 & 1.2 & 7 & 34 \\
4 & Yes & 31 & M & 12 & 28 & 1.7 & 16 & 63 \\
5 & No & 47 & M & 15 & 13 & 2.3 & 18 & 26 \\
6 & Yes & 33 & M & 16 & 18 & 3.3 & 21 & 81 \\
7 & Yes & 22 & M & 11 & 28 & 2.0 & 25 & 88 \\
8 & No & 24 & M & 13 & 24 & 1.3 & 11 & 32 \\
9 & Yes & 35 & M & 16 & 24 & 1.6 & 19 & 59 \\
10 & Yes & 30 & M & 14 & 19 & 2.2 & 30 & 82 \\
11 & No & 43 & M & 15 & 25 & 1.2 & 18 & 47 \\
12 & Yes & 35 & M & 13 & 21 & 2.1 & 25 & 79 \\
13 & No & 26 & M & 14 & 28 & 1.0 & 3 & 6 \\
15 & No & 27 & F & 16 & 17 & 1.2 & 5 & 6 \\
16 & No & 54 & M & 16 & 22 & 1.0 & 0 & 2 \\
17 & No & 27 & M & 16 & 14 & 1.2 & 0 & 2 \\
18 & No & 31 & F & 16 & 8 & 1.2 & 4 & 12 \\
21 & No & 32 & F & 14 & 13 & 1.6 & 13 & 7 \\
\hline
\end{tabular}

M, male; F, female; NA, not available; Edu, education level; CES, Combat Experiences Scale; Anx, Hopkins Symptoms Checklist anxiety scale item average; Dep, Beck Depression Inventory II; PTSD, Clinician-Administered Post-Traumatic Stress Disorder Scale total score.

Fasting blood samples were processed using the PAXgene RNA stabilization system (PreAnalytix, Doncaster, VIC, Australia). Two blood samples were obtained for each subject, one week apart. Blind to clinical status, messenger RNA (mRNA) was converted into PCR templates (cDNA) using the RT2 First Strand kit (SABiosciences, Frederick, MD, USA). SYBR Green-based qRT-PCR was performed for each gene sequence in duplicate and for each sample using the 96-well plate format of the RT2 Profiler PCR Array System (SABiosciences). Thus, four gene expression values were obtained for each gene of interest for each subject (duplicate PCR reactions from two samples). Control reactions were included to test for genomic DNA contamination and efficiency of the reverse transcription of the PCR itself. The samples were processed using a real-time qRT-PCR system (Applied Biosystems 7500; Life Technologies, Carlsbad, CA, USA) and expression values were calculated using the delta-delta $\mathrm{Ct}$ method (33) after the values were normalized according to the $\beta 2$ microglobulin housekeeping gene.

Data analysis. The first quality control applied to the data was to set a maximum for the threshold cycle value $(\mathrm{Ct})$ at 31 cycles, based on values identified for control wells containing a genomic DNA primer set that specifically detected non-transcribed genomic DNA contamination. All four expression values for each gene of interest for each subject were required 
Table III. Correlation of gene expression with clinical phenotypes.

\begin{tabular}{|c|c|c|c|c|c|c|c|c|c|c|}
\hline \multirow[b]{2}{*}{ Gene } & \multicolumn{3}{|c|}{ Continuous variables } & \multicolumn{7}{|c|}{ Dichotomous variables } \\
\hline & PTSD & Anx & Dep & PTSDX & Reexp & Avoid & Hyper & Anx 1.7 & BDI12 & BDI16 \\
\hline IL6ST & -0.10 & -0.04 & -0.13 & -0.09 & -0.21 & -0.13 & -0.07 & 0.17 & -0.04 & 0.03 \\
\hline IL1B & 0.15 & -0.01 & 0.28 & 0.15 & 0.16 & 0.05 & 0.17 & 0.09 & 0.27 & 0.25 \\
\hline TNFRSF10A & 0.20 & 0.08 & 0.15 & 0.23 & 0.14 & 0.06 & 0.14 & 0.33 & 0.10 & 0.15 \\
\hline TNFRSF10B & 0.36 & 0.23 & 0.39 & 0.36 & 0.33 & 0.10 & 0.26 & 0.44 & 0.28 & 0.32 \\
\hline TNFRSF1A & 0.13 & 0.09 & 0.27 & 0.07 & 0.18 & 0.06 & 0.12 & 0.01 & 0.27 & 0.29 \\
\hline TNFRSF1B & 0.26 & 0.03 & 0.21 & 0.27 & 0.22 & 0.07 & 0.20 & 0.30 & 0.10 & 0.13 \\
\hline IL8 & 0.17 & 0.25 & 0.13 & 0.22 & 0.20 & 0.06 & 0.18 & 0.06 & 0.15 & 0.24 \\
\hline IL8RA & 0.19 & 0.12 & 0.28 & 0.13 & 0.17 & 0.04 & 0.16 & 0.16 & 0.31 & 0.35 \\
\hline IL8RB & 0.01 & -0.08 & 0.12 & 0.02 & 0.10 & -0.05 & 0.02 & -0.16 & 0.24 & 0.10 \\
\hline IL16 & 0.30 & 0.08 & 0.24 & 0.32 & 0.23 & 0.15 & 0.24 & 0.34 & 0.12 & 0.19 \\
\hline ADRB2 & 0.20 & 0.28 & 0.14 & 0.12 & 0.20 & 0.04 & 0.05 & 0.19 & 0.09 & 0.12 \\
\hline IL18 & 0.15 & 0.19 & 0.32 & -0.01 & 0.09 & -0.03 & 0.04 & 0.18 & 0.26 & 0.22 \\
\hline FKBP5 & 0.23 & 0.07 & 0.17 & 0.16 & 0.05 & 0.09 & 0.10 & 0.37 & 0.01 & 0.14 \\
\hline S100A12 & -0.06 & 0.03 & 0.18 & -0.01 & -0.15 & -0.02 & -0.03 & 0.02 & 0.16 & 0.08 \\
\hline IL10RA & -0.05 & 0.21 & 0.05 & -0.19 & -0.27 & -0.09 & -0.14 & 0.05 & -0.05 & -0.07 \\
\hline IL10RB & 0.35 & 0.26 & $0.56^{\mathrm{a}}$ & 0.33 & 0.27 & 0.28 & 0.30 & 0.28 & $0.58^{\mathrm{a}}$ & 0.47 \\
\hline IL4R & 0.18 & 0.33 & 0.23 & 0.28 & 0.13 & 0.06 & 0.23 & $0.52^{\mathrm{a}}$ & 0.28 & 0.35 \\
\hline
\end{tabular}

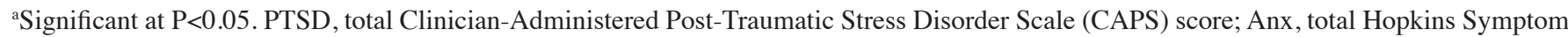
Checklist-25 anxiety scale (HSCLA) score; Dep, total Beck Depression Inventory II (BDI-II) score; PTSDX, CAPS diagnosis; Reexp/Avoid/ Hyper, low vs. high CAPS subscale scores; Anx1.7, significant vs. non-significant HSCLA score; BDI12, no vs. mild or greater depression on the BDI-II; BDI16, no vs. moderate or greater depression on the BDI-II.

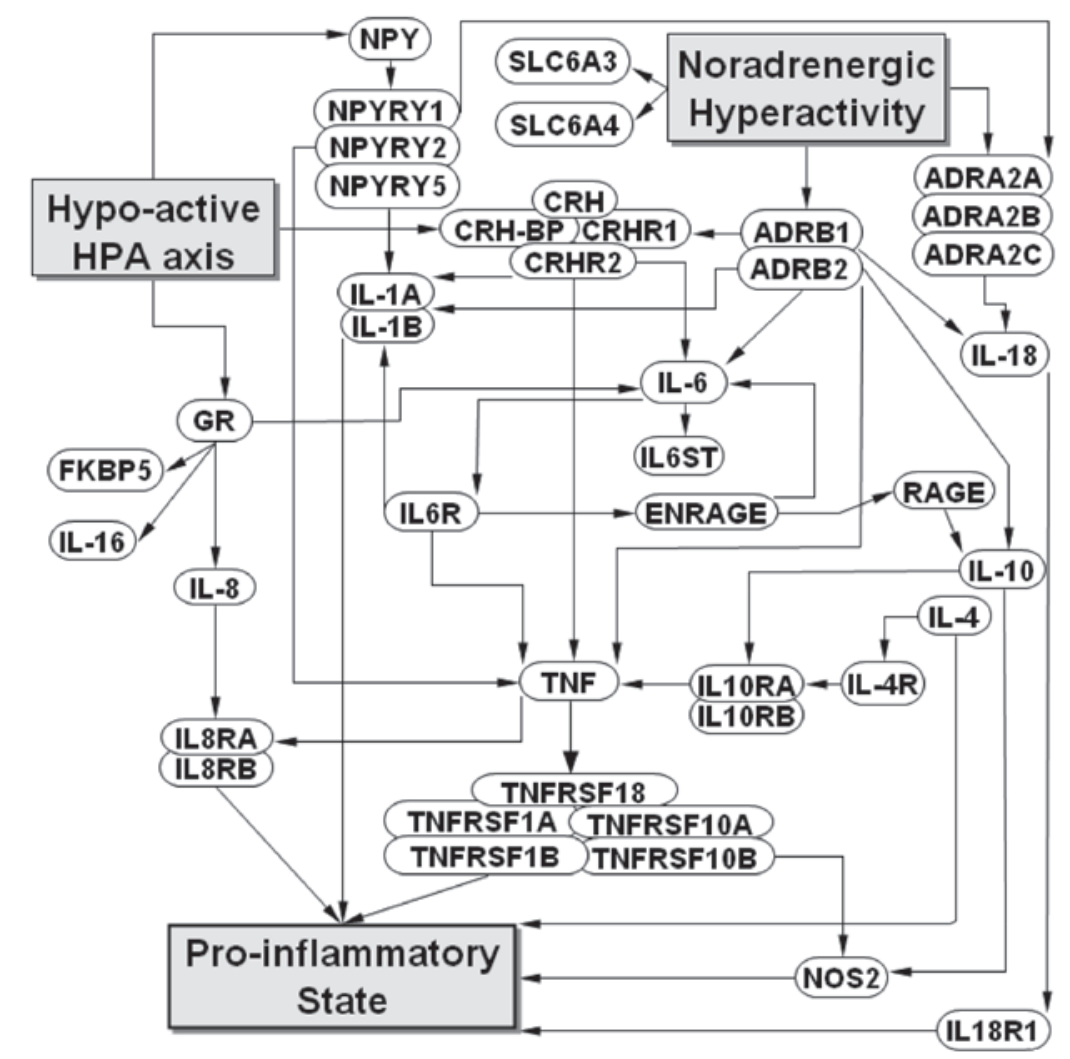

Figure. 1 Theoretical framework for focused gene panel. Arrows indicate regulatory pathways between genes known to be involved in post-traumatic stress disorder (PTSD) and genes linking the hypothalamic-pituitary axis (HPA) and the adrenergic system to inflammation. 
Table IV. Effect size of genes with pattern of differential expression on dichotomous phenotypes.

\section{A. PTSDX}

\begin{tabular}{lccc}
\hline & \multicolumn{2}{c}{ Effect size (mean \pm SE) } & \\
\cline { 2 - 3 } $\begin{array}{l}\text { Gene by } \\
\text { phenotype }\end{array}$ & PTSD $(\mathrm{n}=6)$ & No PTSD $(\mathrm{n}=11)$ & Cohen's $d$ \\
\hline TNFRSF10B & $8.2 \pm 0.32$ & $7.7 \pm 0.18$ & 0.75 \\
IL16 & $6.53 \pm 0.74$ & $5.74 \pm 0.22$ & 0.66 \\
IL10RB & $6.91 \pm 0.13$ & $6.64 \pm 0.13$ & 0.68 \\
IL4R & $5.97 \pm 0.11$ & $5.71 \pm 0.16$ & 0.56 \\
\hline
\end{tabular}

\section{B. Reexp}

\begin{tabular}{llcc}
\hline & \multicolumn{2}{c}{ Effect size (mean \pm SE) } & \\
\cline { 2 - 3 } $\begin{array}{l}\text { Gene by } \\
\text { phenotype }\end{array}$ & High $(\mathrm{n}=7)$ & Low $(\mathrm{n}=10)$ & Cohen's $d$ \\
\hline TNFRSF10B & $8.14 \pm 0.28$ & $7.69 \pm 0.19$ & 0.68 \\
IL16 & $6.34 \pm 0.65$ & $5.79 \pm 0.24$ & 0.44 \\
IL10RB & $6.86 \pm 0.12$ & $6.65 \pm 0.14$ & 0.53 \\
IL4R & $5.87 \pm 0.14$ & $5.75 \pm 0.17$ & 0.25 \\
\hline
\end{tabular}

C. Avoid

\begin{tabular}{llcc}
\hline \multirow{2}{*}{$\begin{array}{l}\text { Gene by } \\
\text { phenotype }\end{array}$} & \multicolumn{2}{c}{ Effect size $($ mean \pm SE) } & \\
\cline { 2 - 3 } & High $(\mathrm{n}=8)$ & Low $(\mathrm{n}=9)$ & Cohen's $d$ \\
\hline TNFRSF10B & $7.95 \pm 0.29$ & $7.81 \pm 0.19$ & 0.20 \\
IL16 & $6.21 \pm 0.58$ & $5.85 \pm 0.26$ & 0.29 \\
IL10RB & $6.85 \pm 0.1$ & $6.63 \pm 0.16$ & 0.55 \\
IL4R & $5.83 \pm 0.13$ & $5.77 \pm 0.18$ & 0.13 \\
\hline
\end{tabular}

D. Hyper

\begin{tabular}{llcc}
\hline & \multicolumn{2}{c}{ Effect size (mean \pm SE) } & \\
\cline { 2 - 3 } $\begin{array}{l}\text { Gene by } \\
\text { phenotype }\end{array}$ & High $(\mathrm{n}=7)$ & Low $(\mathrm{n}=10)$ & Cohen's $d$ \\
\hline TNFRSF10B & $8.09 \pm 0.29$ & $7.73 \pm 0.19$ & 0.54 \\
IL16 & $6.36 \pm 0.65$ & $5.78 \pm 0.24$ & 0.47 \\
IL10RB & $6.87 \pm 0.12$ & $6.64 \pm 0.14$ & 0.58 \\
IL4R & $5.92 \pm 0.1$ & $5.71 \pm 0.18$ & 0.45 \\
\hline
\end{tabular}

E. Anx1.7 (Anxiety)

\begin{tabular}{lccc}
\hline & \multicolumn{2}{c}{ Effect size $($ mean \pm SE $)$} & \\
\cline { 2 - 3 } Gene by & $\begin{array}{l}\text { Clinically } \\
\text { significant } \\
\text { phenotype }\end{array}$ & $\begin{array}{c}\text { Clinically } \\
\text { insignificant } \\
(\mathrm{n}=6)\end{array}$ & Cohen's $d$ \\
\hline TNFRSF10B & $8.28 \pm 0.31$ & $7.67 \pm 0.19$ & 0.92 \\
IL16 & $6.59 \pm 0.72$ & $5.73 \pm 0.25$ & 0.70 \\
IL10RB & $6.91 \pm 0.13$ & $6.7 \pm 0.13$ & 0.55 \\
IL4R & $6.09 \pm 0.07$ & $5.6 \pm 0.16$ & 1.17 \\
\hline
\end{tabular}

Table IV. Continued.

F. BDI12 (depression)

\begin{tabular}{llcc}
\hline & \multicolumn{2}{c}{ Effect size $($ mean \pm SE $)$} & \\
\cline { 2 - 3 } $\begin{array}{l}\text { Gene by } \\
\text { phenotype }\end{array}$ & $\begin{array}{l}\geq \text { Mild } \\
(\mathrm{n}=9)\end{array}$ & $\begin{array}{c}\text { Insignificant } \\
(\mathrm{n}=8)\end{array}$ & Cohen's $d$ \\
\hline TNFRSF10B & $8.05 \pm 0.23$ & $7.68 \pm 0.23$ & 0.55 \\
IL16 & $6.16 \pm 0.51$ & $5.86 \pm 0.3$ & 0.24 \\
IL10RB & $6.95 \pm 0.1$ & $6.5 \pm 0.13$ & 1.35 \\
IL4R & $5.92 \pm 0.1$ & $5.67 \pm 0.21$ & 0.54 \\
\hline
\end{tabular}

G. BDI16 (depression)

\begin{tabular}{lccc}
\hline & \multicolumn{2}{c}{ Effect size (mean \pm SE $)$} & \\
\cline { 2 - 3 } $\begin{array}{l}\text { Gene by } \\
\text { phenotype }\end{array}$ & $\begin{array}{c}\geq \text { Moderate } \\
(\mathrm{n}=8)\end{array}$ & $\begin{array}{c}<\text { Moderate } \\
(\mathrm{n}=9)\end{array}$ & Cohen's $d$ \\
\hline TNFRSF10B & $8.1 \pm 0.26$ & $7.67 \pm 0.21$ & 0.63 \\
IL16 & $6.26 \pm 0.57$ & $5.81 \pm 0.27$ & 0.36 \\
IL10RB & $6.93 \pm 0.11$ & $6.56 \pm 0.14$ & 0.99 \\
IL4R & $5.96 \pm 0.1$ & $5.65 \pm 0.19$ & 0.68 \\
\hline
\end{tabular}

PTSD, post-traumatic stress disorder; PTSDX, Clinician-Administered PTSD Scale (CAPS) diagnosis; Reexp/Avoid/Hyper, low vs. high CAPS subscale scores; Anx1.7, significant vs. non-significant Hopkins Symptom Checklist-25 anxiety scale (HSCLA) score; BDI12, no vs. mild or greater depression on the Beck Depression Inventory II (BDI-II); BDI16, no vs. moderate or greater depression on the BDI-II.

to be under the maximum $\mathrm{Ct}$ for the gene to be included in further analyses.

The second quality control was to assess the replicability of $\mathrm{Ct}$ values for each gene. A threshold for variance in values from duplicate PCR reactions was set at $\leq 2$ cycles. When the $\mathrm{Ct}$ values for the same gene on the same plate varied by $>2$ cycles, only the $\mathrm{Ct}$ value that was consistent with the average $\mathrm{Ct}$ values from the replicate sample (within two cycles) was used and the outlier value was considered to be a test error and eliminated from further analysis.

The third quality control for the remaining genes was to examine reliability for each gene. The between-person variability had to be significantly larger than pooled within-person variability (by an F-test from a one-way analysis of variance; $\mathrm{P}<0.05)$ for a gene to be retained.

Genes passing all three quality controls were analyzed for potential differential expression by phenotypes. The expression value used for each gene for each subject was an average of all the 4 samples. General linear models were applied to dichotomous and continuous data. Since this pilot study was not powered to detect small but significant between-group differences, Cohen's $d$ effect size was calculated for genes showing a pattern of possible differential expression, defined by having all 10 expression values (10 phenotypes), the same valence and at least three expression-phenotype correla- 
Table V. Summary of effect size of gene expression on phenotype.

\begin{tabular}{lllll}
\hline Phenotype & TNFRSF10B & IL16 & IL10RB & IL4R \\
\hline PTSDX & Moderate & Moderate & Moderate & Moderate \\
Reexp & Moderate & Small & Moderate & None \\
Avoid & None & None & Moderate & None \\
Hyper & Moderate & Small & Moderate & Small \\
Anx1.7 & Large & Moderate & Moderate & Large \\
BDI12 & Moderate & None & Large & Moderate \\
BDI16 & Moderate & Small & Large & Moderate \\
\hline
\end{tabular}

Effect size $(d)$ defined by Cohen's $d$ : none, 0; small, 0.30-0.49; moderate, 0.50-0.79; large, $>0.80$. PTSDX, Clinician-Administered Post-Traumatic Stress Disorder Scale (CAPS) diagnosis; Reexp/ Avoid/Hyper, low vs. high CAPS subscale scores; Anx1.7, significant vs. non-significant Hopkins Symptom Checklist-25 anxiety scale (HSCLA) score; BDI12, no vs. mild or greater depression on the Beck Depression Inventory II (BDI-II); BDI16, no vs. moderate or greater depression on the BDI-II.

tions $>0.30$, which is at least a medium effect size as defined by Cohen (34). Ten a priori defined phenotypes were as follows: i) Continuous phenotypes were defined by total CAPS scores (PTSD), item-average scores on HSCLA and total scores on the BDI-II; and ii) dichotomous phenotypes were defined by a PTSD diagnosis on CAPS, low vs. high PTSD subscale scores (re-experiencing, avoidance/numbing, hypervigilance), clinically significant vs. non-significant anxiety on HSCLA and two depression phenotypes on BDI-II (no depression vs. mild or greater depression; no or mild depression vs. moderate or greater depression).

\section{Results}

\section{Quality control}

Threshold cycle value (Ct). Genes of interest (20/42) eliminated from analysis by this quality control were: interleukin $1 \mathrm{~A}$ (IL1A), IL4, IL6, IL10, inducible nitric oxide synthase 2 (NOS2), sodium-dependent dopamine transporter (SLC6A3), 5-hydroxytryptamine transporter (SLC6A4), $\alpha 2 \mathrm{~A}$ adrenoreceptor (ADRA2A), ADRA2B, ADRA2C, $\beta 1$-adrenergic receptor (ADRB1), tumor necrosis factor (TNF) receptor superfamily member 18 (TNFRSF18), neuropeptide Y (NPY), NPY receptor Y1 (NPY1R), NPY2R, NPY5R, corticotropin releasing hormone (CRH), CRH receptor 1 (CRHR1), CRHR2 and $\mathrm{CRH}$ binding protein (CRHBP). None of these eliminated genes had significant inter-assay variance.

Replicability. Only eight outlier values were identified from a total of 1,344 assessments on the second quality control ( $0.6 \%$ test error rate).

Reliability. This quality control eliminated 5 candidate genes; IL6 receptor (IL6R), IL18R1, TNF, nuclear receptor subfamily 3, group C, member 1 glucocorticoid receptor (GR) and receptor for advanced glycosylation end products (RAGE). For the 17 remaining genes, one-week re-test reliability showed a $9 \%$ coefficient of variability for within-person values, which
Table VI. Between group effect size of gene expression by dichotomous phenotype (two shown, PTSD diagnosis and high vs. low anxiety) for genes with correlation $>0.27$ to phenotype.

\begin{tabular}{lccc}
\hline \multirow{2}{*}{$\begin{array}{l}\text { A. PTSDX } \\
\text { Gene by } \\
\text { phenotype }\end{array}$} & \multicolumn{2}{c}{ Effect size (mean \pm PE $)$} & \\
\cline { 2 - 3 } & PTSD $(\mathrm{n}=6)$ & No PTSD $(\mathrm{n}=11)$ & Cohen's $d$ \\
\hline RAGE & $10.67 \pm 0.28$ & $10.04 \pm 0.22$ & 0.88 \\
TNFRSF10B & $8.2 \pm 0.32$ & $7.7 \pm 0.18$ & 0.75 \\
IL10RB & $6.91 \pm 0.13$ & $6.64 \pm 0.13$ & 0.68 \\
IL16 & $6.53 \pm 0.74$ & $5.74 \pm 0.22$ & 0.66 \\
IL 6R & $5.04 \pm 0.33$ & $4.67 \pm 0.16$ & 0.58 \\
IL4R & $5.97 \pm 0.11$ & $5.71 \pm 0.16$ & 0.56 \\
IL18R & $9.07 \pm 0.17$ & $8.87 \pm 0.10$ & 0.55 \\
\hline
\end{tabular}

B. Anx1.7 (anxiety)

\begin{tabular}{lccc}
\hline & \multicolumn{2}{c}{ Effect size $($ mean \pm SE $)$} & \\
\cline { 2 - 3 } Gene by & $\begin{array}{c}\text { Clinically } \\
\text { significant } \\
\text { phenotype }\end{array}$ & $\begin{array}{c}\text { Clinically } \\
\text { insignificant } \\
(\mathrm{n}=6)\end{array}$ & \\
\hline IL4R & $6.09 \pm 0.07$ & $5.6 \pm 0.16$ & 1.17 \\
RAGE & $10.72 \pm 0.26$ & $10.03 \pm 0.24$ & 0.96 \\
TNFRSF10B & $8.28 \pm 0.31$ & $7.67 \pm 0.19$ & 0.92 \\
FKBP5 & $5.63 \pm 0.32$ & $5.23 \pm 0.10$ & 0.75 \\
IL16 & $6.59 \pm 0.72$ & $5.73 \pm 0.25$ & 0.70 \\
IL6R & $5.08 \pm 0.33$ & $4.64 \pm 0.16$ & 0.70 \\
TNF10A & $9.95 \pm 0.43$ & $9.41 \pm 0.18$ & 0.69 \\
TNF1B & $6.92 \pm 0.59$ & $6.30 \pm 0.23$ & 0.59 \\
IL10RB & $6.91 \pm 0.13$ & $6.7 \pm 0.13$ & 0.55 \\
\end{tabular}

PTSD, post-traumatic stress disorder;PTSDX, Clinician-Administered PTSD Scale (CAPS) diagnosis; Anx 1.7, significant vs. non-significant Hopkins Symptom Checklist-25 anxiety scale (HSCLA) score.

is consistent with high-quality data from biological systems (typically 5-10\%).

\section{Differential expression by phenotype}

Descriptive. Table I shows no differences between PTSD and no PTSD groups in demographic variables or combat exposure. As expected, PTSD subjects had more symptoms of depression and anxiety. Relevant data for each subject are provided in Table II.

Mean comparisons. Three gene-by-phenotype tests were statistically significant for between-group gene expression; IL10RB on depression, and BDI12 and IL4R on anxiety (Table III). However, with 100 comparisons, 5 may be significant by chance alone.

Effect size. Four genes met the criteria for having a pattern of possible differential expression; TNFRSF10B, IL16, IL10RB and IL4R. Table IV shows the effect size by phenotype for each gene and these effects are summarized in Table V. 


\section{Discussion}

This pilot study highlights the importance of methods utilizing GEA on the interpretation of results, and identifies possible differential expression patterns between PTSD and control subjects using a theoretically driven approach. Conclusions with regard to differential expression patterns are preliminary due to the chosen GEA technology, target genes, sample size and selection of phenotypes. Twenty genes eliminated due to low expression (high $\mathrm{Ct}$ ) may or may not be significant contributors to PTSD and require further investigation by adding a pre-amplification step between mRNA isolation and the qRT-PCR analysis (35-37). Furthermore, three of the five genes excluded from analysis at the reliability control step (IL6R, IL18R1 and RAGE) showed a pattern of possible increased differential expression on phenotypes. Had strict quality control measures not been applied in the present study, RAGE in particular would have been reported to exhibit the strongest overall signal of possible differential expression by phenotypes. Notably, interactions between RAGE and its ligands have been suggested to result in pro-inflammatory gene activation (38), which may render RAGE an important regulatory gene in the proposed model for PTSD (Fig. 1). Similarly, effect size analyses were applied to these data conservatively; these were conducted as the study was preliminary and underpowered. Had the third quality control step been ignored and we were to report genes that demonstrated a GEA-by-phenotype correlation of $>0.27$ and a moderate or greater effect size (rather than define 'possible differential expression' using a higher standard), more between-group possible differential expressions would have been reported, as shown in Table VI, for only two of the phenotypes. Thus, strict quality control methods may enhance specificity at the expense of sensitivity. At the current stage of this research, it is critical to obtain specific markers at the expense of sensitive markers within a theoretical framework. Thus, there are numerous genes which are not in this proposed model that may be markers for PTSD. Finally, the phenotypes chosen may or may not be the most appropriate to discover between-group expression effects. There is a fair debate with regard to the relevance of clinical category to biology, where endophenotypes may provide more information on the range of psychiatric illnesses and allow for more powerful assessment of genetic linkage (39).

Three of the four genes exhibiting a pattern of possible increased differential expression on PTSD and associated phenotypes, TNFRSF10B, IL10RB and IL4R, are involved in the regulation pathway of pro-inflammation from noradrenergic hyperactivity. The fourth gene, IL16, is known to be regulated by GR, the receptor to which cortisol and other glucocorticoids bind. Notably, GR expression valence, while non-significant, was negative for all the phenotypes and had a significant negative correlation with combat trauma exposure $(\mathrm{r}=-0.59)$. These results are consistent with our theoretical model and the results of a recent study (40). Future studies are required to understand the association between the relative degree of differential expression in mRNA and clinical phenotypes with clinical bioactivity, potentially as assessed by corresponding peripheral markers.

Conclusions with regard to differential expression patterns are preliminary due to the GEA technology utilized in the present study. Furthermore, the sample size was small. Twenty genes eliminated due to low expression may or may not be significant contributors to PTSD. This may be further investigated by adding a pre-amplification step between mRNA isolation and qRT-PCR analysis.

\section{Acknowledgements}

Funding was provided by PIRE Corporate Development (grant no. 9239). The authors would like to thank and honor the members of our military, and appreciate the technical assistance provided by Everett Lowry, Tri Luu, Umang Dave, Jonathon Vigil, Valerie Wada, Liz Wozniak and Linda Nguyen.

\section{References}

1. Koenen KC: Nature-nurture interplay: genetically informative designs contribute to understanding the effects of trauma and interpersonal violence. J Interpers Violence 20: 507-512, 2005.

2. Baker DG, Ekhator NN, Kasckow JW, et al: Higher levels of basal serial CSF cortisol in combat veterans with posttraumatic stress disorder. Am J Psychiatry 162: 992-994, 2005.

3. Bremner D, Vermetten E and Kelley ME: Cortisol, dehydroepiandrosterone, and estradiol measured over 24 hours in women with childhood sexual abuse-related posttraumatic stress disorder. J Nerv Ment Dis 195: 919-927, 2007.

4. Glover DA and Poland RE: Urinary cortisol and catecholamines in mothers of child cancer survivors with and without PTSD. Psychoneuroendocrinology 27: 805-819, 2002.

5. Mason JW, Giller EL, Kosten TR, Ostroff RB and Podd L: Urinary free-cortisol levels in posttraumatic stress disorder patients. J Nerv Ment Dis 174: 145-149, 1986.

6. Rohleder N and Karl A: Role of endocrine and inflammatory alterations in comorbid somatic diseases of post-traumatic stress disorder. Minerva Endocrinol 31: 273-288, 2006.

7. Thaller V, Vrkljan M, Hotujac L and Thakore J: The potential role of hypocortisolism in the pathophysiology of PTSD and psoriasis. Coll Antropol 23: 611-619, 1999.

8. Yehuda R, Southwick SM, Nussbaum G, Wahby V, Giller EL Jr and Mason JW: Low urinary cortisol excretion in patients with posttraumatic stress disorder. J Nerv Ment Dis 178: 366-369, 1990.

9. Yehuda R, Giller EL Jr and Mason JW: Psychoneuroendocrine assessment of posttraumatic stress disorder: current progress and new directions. Prog Neuropsychopharmacol Biol Psychiatry 17: 541-550, 1993.

10. Yehuda R, Boisoneau D, Lowy MT and Giller EL Jr: Dose-response changes in plasma cortisol and lymphocyte glucocorticoid receptors following dexamethasone administration in combat veterans with and without posttraumatic stress disorder. Arch Gen Psychiatry 52: 583-593, 1995.

11. Rohleder D, Kiefer W and Petrich W: Quantitative analysis of serum and serum ultrafiltrate by means of Raman spectroscopy. Analyst 129: 906-911, 2004.

12. Blanchard EB, Hickling EJ, Buckley TC, Taylor AE, Vollmer A and Loos WR: Psychophysiology of posttraumatic stress disorder related to motor vehicle accidents: replication and extension. J Consult Clin Psychol 64: 742-751, 1996.

13. Yehuda R, Siever LJ, Teicher MH, et al: Plasma norepinephrine and 3-methoxy-4-hydroxyphenylglycol concentrations and severity of depression in combat posttraumatic stress disorder and major depressive disorder. Biol Psychiatry 44: 56-63, 1998.

14. Bremner JD, Elzinga B, Schmahl C and Vermetten E: Structural and functional plasticity of the human brain in posttraumatic stress disorder. Prog Brain Res 167: 171-186, 2008.

15. Lanius RA, Bluhm R, Lanius U and Pain C: A review of neuroimaging studies in PTSD: heterogeneity of response to symptom provocation. J Psychiatr Res 40: 709-729, 2006.

16. Shin LM, Wright CI, Cannistraro PA, Wedig MM, et al: A functional magnetic resonance imaging study of amygdala and medial prefrontal cortex responses to overtly presented fearful faces in posttraumatic stress disorder. Arch Gen Psychiatry 62: 273-281, 2005 . 
17. Kolassa IT, Wienbruch C, Neuner F, et al: Altered oscillatory brain dynamics after repeated traumatic stress. BMC Psychiatry 7: 56, 2007.

18. Baker DG, Ekhator NN, Kasckow JW, et al: Plasma and cerebrospinal fluid interleukin-6 concentrations in posttraumatic stress disorder. Neuroimmunomodulation 9: 209-217, 2001.

19. Maes M,Lin AH, Delmeire L, et al: Elevated serum interleukin-6 (IL-6) and IL-6 receptor concentrations in posttraumatic stress disorder following accidental man-made traumatic events. Biol Psychiatry 45: 833-839, 1999.

20. Spivak B, Shohat B, Mester R, et al: Elevated levels of serum interleukin-1 beta in combat-related posttraumatic stress disorder. Biol Psychiatry 42: 345-348, 1997.

21. Tucker P, Masters B and Nawar O: Topiramate in the treatment of comorbid night eating syndrome and PTSD: a case study. Eat Disord 12: 75-78, 2004

22. von Känel R, Hepp U, Kraemer B, et al: Evidence for low-grade systemic proinflammatory activity in patients with posttraumatic stress disorder. J Psychiatr Res 41: 744-752, 2007.

23. Segman RH, Shefi N, Goltser-Dubner T, Friedman N, Kaminski N and Shalev AY: Peripheral blood mononuclear cell gene expression profiles identify emergent post-traumatic stress disorder among trauma survivors. Mol Psychiatry 10: 500-513, 2005.

24. Su TP, Zhang L, Chung MY, et al: Levels of the potential biomarker p11 in peripheral blood cells distinguish patients with PTSD from those with other major psychiatric disorders. J Psychiatr Res 43: 1078-1085, 2009.

25. Yehuda R, Cai G, Golier JA, et al: Gene expression patterns associated with posttraumatic stress disorder following exposure to the World Trade Center attacks. Biol Psychiatry 66: 708-711, 2009.

26. Zieker J, Zieker D, Jatzko A, et al: Differential gene expression in peripheral blood of patients suffering from post-traumatic stress disorder. Mol Psychiatry 12: 116-118, 2007.

27. Koenen KC, De Vivo I, Rich-Edwards J, Smoller JW, Wright RJ and Purcell SM: Protocol for investigating genetic determinants of posttraumatic stress disorder in women from the Nurses' Health Study II. BMC Psychiatry 9: 29, 2009.

28. First MB, Spitzer RL, Gibbon $M$ and Williams JBW (eds): Structured Clinical Interview for DSM-IV Axis I Disorders. American Psychiatric Press, Inc., Washington, DC, 2001.
29. Blake DD, Weathers FW, Nagy LM, et al: The development of a Clinician-Administered PTSD Scale. J Trauma Stress 8: 75-90, 1995.

30. Keane TM, Fairbank JA, Caddell JM, Zimering RT, Taylor KL and Mora CA: Clinical evaluation of a measure to assess combat exposure. Psychol Assess 1: 53-55, 1989.

31. Beck AT, Steer RA and Brown GK (eds): Manual for Beck Depression Inventory-II. Psychological Corporation, San Antonio, TX, 1996.

32. Derogatis LR, Lipman RS, Rickels K, Uhlenhuth EH and Covi L: The Hopkins Symptom Checklist (HSCL): a self-report symptom inventory. Behav Sci 19: 1-15, 1974.

33. Calcagno AM, Chewning KJ, Wu CP and Ambudkar SV: Plasma membrane calcium ATPase (PMCA4): a housekeeper for RT-PCR relative quantification of polytopic membrane proteins. BMC Mol Biol 7: 29, 2006.

34. Cohen J: A power primer. Psychol Bull 112: 155-159, 1992.

35. Laurell C, Wirta V, Nilsson P and Lundeberg J: Comparative analysis of a 3' end tag PCR and a linear RNA amplification approach for microarray analysis. J Biotechnol 127: 638-646, 2007.

36. Kurimoto K, Yabuta Y, Ohinata Y and Saitou M: Global single-cell cDNA amplification to provide a template for representative high-density oligonucleotide microarray analysis. Nat Protoc 2: 739-752, 2007.

37. Kube DM, Savci-Heijink CD, Lamblin AF, et al: Optimization of laser capture microdissection and RNA amplification for gene expression profiling of prostate cancer. BMC Mol Biol 8: 25, 2007.

38. Bierhaus A, Schiekofer S, Schwaninger M, et al: Diabetes-associated sustained activation of the transcription factor nuclear factor-kappaB. Diabetes 50: 2792-2808, 2001.

39. Almasy L, Gur RC, Haack K, Cole SA, Calkins ME, Peralta JM, Hare E, Prasad K, Pogue-Geile MF, Nimgaonkar V and Gur RE: A genome screen for quantitative trait loci influencing schizophrenia and neurocognitive phenotypes. Am J Psychiatry 165: $1185-1192,2008$

40. O'Donovan A, Sun B, Cole S, et al: Transcriptional control of monocyte gene expression in post-traumatic stress disorder. Dis Markers 30: 123-132, 2011. 